\title{
THE IMPACT OF INTRINSIC AND EXTRINSIC MOTIVATION ON JOB PERFORMANCE IN A PARTICIPATIVE BUDGET SETTING: A RESEARCH NOTE
}

\author{
Suria Zainuddin ${ }^{1}$ and Dalilawati Zainal
}

\begin{abstract}
Most of the studies that examine the variable for motivation only concentrate on either intrinsic or extrinsic motivation. However, this study highlights the importance of both types of motivation in increasing job performance. Specifically, the objective of this paper is to examine the impact of intrinsic and extrinsic motivation on job performance in a participative budget setting. Based on the survey questionnaire of 108 managers, data are analysed using Partial Least Squares. The results show that budget participation increases intrinsic motivation, and that intrinsic motivation leads to the extrinsic motivation, which, in turn, increases job performance.
\end{abstract}

Keywords: Budget participation; job performance; intrinsic motivation; extrinsic motivation

\section{Introduction}

The objective of this paper is to examine the impact of two forms of motivation - intrinsic and extrinsic - on job performance in a participative budget setting. Thus far, most of the studies (except Wong-On-Wing et al., 2010) that examine the motivation variable in accounting literature focus on either extrinsic or intrinsic motivation, but not both types of motivation. While Wong-On-Wing et al. (2010) examine the effect of both types of motivation on budget participation and performance, this study examines the effect of participation in budgeting on both types of motivation, and its effect on job performance. Thus, this study contributes to the existing literature by highlighting the importance of both types of motivation (extrinsic and intrinsic motivation) in a participative budget setting. In particular, this paper attempts to examine whether both intrinsic and extrinsic

\footnotetext{
Corresponding author: Dr Suria Zainuddin is a Senior Lecturer at the Faculty of Business and Accountancy, University of Malaya, email: suriaz@um.edu.my. Dr Dalilawati Zainal is a Senior Lecturer at the Faculty of Business and Accountancy, University of Malaya.
} 
motivation have any impact in increasing job performance. Intrinsic motivation refers to the execution of one task because it is inherently interesting or enjoyable (Ryan and Deci, 2000) while fulfilling personal satisfaction, whereas extrinsic motivation refers to the execution of one task because it leads to a separable outcome (Ryan and Deci, 2000) or additional rewards that could be achieved upon fulfilling the task.

Although research in participative budgeting began in the 1940s, it is still relevant and is attracting the attention of various researchers in examining the effectiveness of participation in influencing the attitude and behaviour of employees (for example, Chong and Chong, 2002; Lau and Sholihin, 2005; Agbejule and Saarikoski, 2006; Chong and Johnson, 2007). Previous studies that have extensively examined the relationship between budget participation and the performance of managers provide no conclusive evidence. The findings are mixed, with some studies showing a significant positive relationship (Merchant, 1981; Brownell, 1982; Brownell and McInnes, 1986), while others are unable to relate budget participation with performance (Kenis, 1979). Thus, the relationship may not be direct; it may be indirect through other mediating variables.

Thus far, the mediating variables that have been examined include attitude (Milani, 1975), budget adequacy and organisational commitment, (Nouri and Parker, 1998), and fairness perceptions and trust (Lau and Tan, 2006). Brownell and McInnes (1986) examine the mediating role of motivation in the relationship between budget participation and performance; however, they do not examine the different forms of motivation. Brownell (1983), Dermer (1975) and Wong-OnWing et al. (2010) assert that there are two forms of motivation - intrinsic and extrinsic. These forms are differentiated based on the different motives of people for performing one task. However, most of the studies focus on either extrinsic or intrinsic motivation, but not both types of motivation (except Wong-On-Wing et al., 2010). Thus, this study aims to bridge the gap in the extant literature by providing empirical evidence for the joint consideration of intrinsic and extrinsic motivation in the relationship between budget participation and job performance, and offering insights into which intrinsic and extrinsic motivation may enhance job performance.

The rest of the paper is organised as follows. In the next section, hypotheses development is presented, followed by the methodology used and the results of the study. The last section presents the conclusion and the discussion of the results.

\section{Hypothesis Development}

\subsection{Budget Participation and Intrinsic Motivation}

Budget participation involves a process through which managers provide views and have some influence over the budget that is prepared by the management (Magner et al., 1995; Shields and Shields, 1998). It enables the involvement of managers in budgetary decisions and provides possibilities for the influence of 
the final budget. In addition, budget participation facilitates communication, increases commitment and job satisfaction, and, in turn, enhances job performance (Jermias and Setiawan, 2008).

Participation in the budgetary process enables the agreement of the organisational financial goal among managers of all levels. Through participation, sub-unit managers have the opportunity to provide essential information regarding their task requirement, since they are directly involved in their work. Thus, involving them in the decision-making process will enable their superior to design a better budget-goal, which, in turn, will motivate the employees to achieve the budget (Shields and Shields, 1998). It is theorised that for the budgets that are set through participation, the level of aspiration of managers will increase (Becker and Green, 1962). These managers are intrinsically motivated to achieve the budget because the budget has their voice and it is interesting and enjoyable to achieve what they have helped to create. It also increases their sense of control, greater ego involvement and increased goal acceptance (Wong-On-Wing et al., 2010). It fulfils their personal satisfaction and self-accomplishment. Kenis (1979) and Merchant (1981) also show that budget participation has a significant positive relationship with motivation. Thus the following hypothesis is developed:

\section{$\mathrm{H}_{1}$ : There is a positive relationship between budget participation and intrinsic motivation}

\subsection{Intrinsic Motivation and Extrinsic Motivation}

Extrinsic motivation refers to the additional rewards that could be achieved upon satisfying the budgeted goal. Among the outcomes of extrinsic rewards used in Brownell's (1983) empirical study are pay raise, respect from boss and other employees, special rewards or recognition, and promotion. In a recent study, Wong-On-Wing et al. (2010) classify extrinsic motivation into autonomous and controlled extrinsic motivation, which is based on the self-determination theory. Autonomous extrinsic motivation is "when behaviour is performed out of choice because individuals value the behaviour" (Wong-On-Wing et al., 2010, p.135). Controlled or non-autonomous extrinsic motivation is "when one's behaviour allows for satisfaction of an external demand or reward contingency" (WongOn-Wing et al., 2010, p. 135).

Dermer (1975) suggests that extrinsic motivation is related to intrinsic motivation. This means that when there is an intrinsic motivation, there is an increased need for extrinsic motivation. In other words, managers who are intrinsically motivated will work effortlessly to accomplish their self-satisfaction. Upon achieving their own satisfaction, they are motivated to gain potential external incentives and rewards for the fulfilment of the task. Hofstede (1968) also asserts that intrinsic motivation is a necessary corequisite for extrinsic motivation (Dermer, 1975). According to the expectancy theory, an individual's motivation to 
pursue an action is due to the perceived value of an outcome and the expectancy of achieving that outcome (Kren, 1990). Thus, the attractiveness of the rewards and the perceptions of attaining those rewards motivate the individual to perform job; the rewards are more motivating when there is an element of intrinsic motivation. Managers are strongly motivated for extrinsic reward when they enjoy their work. Thus, there is a positive significant relationship between intrinsic and extrinsic motivation, for which the following hypothesis is suggested:

\section{$\mathrm{H}_{2}$ : There is a positive relationship between intrinsic motivation and extrinsic motivation}

\subsection{Extrinsic Motivation and Job Performance}

In the context of a participative budgeting, based on a goal setting theory, the budget serves as a goal to be achieved. The fulfilment of self-satisfaction, and extrinsic rewards and incentives upon achieving a budget goal encourages them to exert more effort in fulfilling the requirements of a task. This motivation device can enhance not only the manager's performance but also the performance of the firms. Moreover, in a goal setting situation, a clear, tight but attainable goal is the most preferred type of budget (Becker and Green, 1962; Hofstede, 1968; Kenis, 1979; Locke and Latham, 1984). A budget specified by the management through the participation process enables the creation of an attainable budget and builds the motivation of managers to achieve the targeted goal (Merchant, 1981).

Previous research has suggested the positive effects of motivation in enhancing performance (Brownell and McInnes, 1986; Kenis, 1979; Shields and Shields, 1998). This study also proposes that motivation may increase the performance of employees.

\section{$\mathrm{H}_{3}$ : There is a positive relationship between extrinsic motivation and job performance}

The theoretical model is shown in Figure 1.

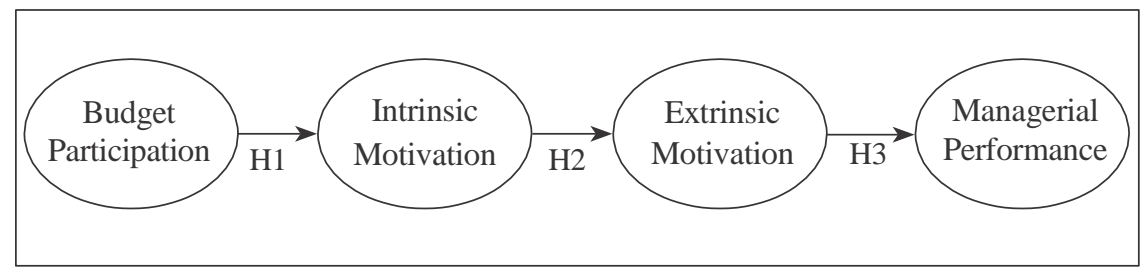

Figure 1: Theoretical Framework 


\section{Research Method}

\section{Sample and Procedure}

A survey questionnaire was used to collect data from a cross-functional area of firms listed in Bursa Malaysia. The survey was sent by mail to individual managers who have budget responsibilities. The distributed surveys were accompanied by a cover letter, instructions for completing the survey, and a self-addressed postage-paid envelope to minimise the response bias. A total of 1000 surveys were distributed, of which 108 (11\%) useable responses were accepted for data analysis.

\section{Measurement of Variables}

The survey questionnaires were designed based on the established measurements, which were developed by previous studies. Except for the job performance variable, the response scale for all the variables comprised a five-point Likert scale, ranging from 1 (strongly disagree) to 5 (strongly agree).

Budget participation was assessed using the instrument developed by Milani (1975), which consisted of a six-item scale that has been used extensively and tested broadly in budget participation studies with high Cronbach alpha values. Studies that have adopted this instrument include Brownell and McInnes (1986), Chong and Chong (2002), Lau and Tan (2006), and Nouri and Parker (1998).

Intrinsic motivation was measured using a three-item scale - personal growth and development, a feeling of accomplishment and a sense of personal satisfaction - used in Dermer (1975). This measurement has also been applied in Merchant (1981) and Kenis (1979).

Extrinsic motivation was measured using the instrument adapted from the procedure developed by Lawler and Suttle (1973), and follows the categorization of extrinsic motivation provided by Brownell (1983), and Brownell and McInnes (1986), which includes security, recognition, and respect from boss.

Job performance was assessed using a nine-item scale developed by Mahoney et al. (1965). This performance instrument is consistent with prior research (for example, Brownell and McInnes, 1986; Chong and Chong, 2002; Lau and Lim, 2002). The response scale is a five-point Likert scale ranging from 1 (below average) to 5 (above average). It consists of eight performance dimensions of planning, investigating, coordinating, evaluating, supervising, staffing, negotiating and representing.

\section{Results}

The demographic data shows that most of the respondents have work experience of at least 5 years. The respondents are attached to several functional areas including Finance, Human Resource, and Production and Marketing. Almost similar responses come from the manufacturing and services sectors. The manufacturing sector includes the following industries: chemical, gas and petroleum; electrical and electronics; transport and automotive; and food and beverage. The service 
sector includes industries, such as telecommunication, construction, plantation and fast moving consumer goods. More than $50 \%$ of the firms have more than 200 employees with total assets worth more than RM50 million.

Table 1 presents the means and descriptive statistics for all study variables. It shows that the highest mean was recorded for the intrinsic motivation variable, while the perceptions of the respondents on the rest of the variables were moderately high.

Table 1: Descriptive Statistics for Variables (N=108)

\begin{tabular}{|l|c|c|c|c|c|c|}
\hline \multirow{2}{*}{ Variable } & \multirow{2}{*}{ Mean } & \multirow{2}{*}{\begin{tabular}{c} 
Std. \\
\cline { 4 - 7 }
\end{tabular}} & & \multicolumn{2}{c|}{ Actual Range } & \multicolumn{2}{c|}{ Theoretical Range } \\
\cline { 4 - 7 } & & Deviation & Min & Max & Min & Max \\
\hline Budget Participation & 3.59 & 0.82 & 1.00 & 5.00 & 1.00 & 5.00 \\
\hline Intrinsic Motivation & 4.24 & 0.89 & 1.00 & 5.00 & 1.00 & 5.00 \\
\hline Extrinsic Motivation & 3.22 & 0.79 & 1.00 & 5.00 & 1.00 & 5.00 \\
\hline Job Performance & 3.73 & 0.58 & 1.88 & 5.00 & 1.00 & 5.00 \\
\hline
\end{tabular}

\section{Partial Least Squares - Results}

Partial Least Squares (PLS) were used in order to test the hypotheses developed since it enables the analysis of all the paths simultaneously (Hsu et al, 2006). To determine the reliability and validity of the model, internal consistency reliability, convergent validity and discriminant validity are examined.

The loading of each item to its individual construct assesses the reliability of the items. As shown in Table 2, most of the items loaded at more than 0.7 on their own construct, which indicates acceptable reliability (Hulland, 1999). Convergent validity is assessed by looking at the composite reliability of constructs. Table 3 shows the composite reliability of above 0.8 for all constructs (Fornell and Larcker, 1981). More evidence on reliability is shown from the value of Cronbach's $\alpha$. It shows that all the constructs had satisfactory reliability with the value of more than 0.8 . Table 3 shows the average variance extracted (AVE) of more than 0.5 , which signifies that all the constructs satisfy the requirement of convergent validity (Fornell and Larcker, 1981). For the discriminant validity, all of the measurement items loaded higher on their own constructs than the cross loading on other constructs, as portrayed in Table 2 (Chin, 1998). In addition, Table 3 shows the square root of AVE as more than the correlations among the different constructs, which indicates that more variance is shared between the construct and its indicators than it shares with other constructs in the same model (Chin, 1998; Fornell and Larcker, 1981). Tables 2 and 3 demonstrate that all the constructs have met the requirements of internal reliability and validity.

Figure 2 shows the $\mathrm{R}^{2}$ of the dependent variables, the path coefficients ( $\beta$ estimates) and its significance value (p-values). Approximately $14 \%$ of the 
variances in intrinsic motivation are explained by budget participation, while intrinsic motivation explains $22 \%$ of the variance in extrinsic motivation. Extrinsic motivation only explains $12 \%$ of the variance in job performance.

Table 2: Factor Loadings from PLS Measurement Model

\begin{tabular}{|c|c|c|c|c|}
\hline & BP & Extrinsic & Intrinsic & MP \\
\hline BP1 & $\mathbf{0 . 7 2}$ & 0.03 & 0.14 & 0.23 \\
\hline BP2 & $\mathbf{0 . 8 3}$ & 0.13 & 0.35 & 0.23 \\
\hline BP3 & $\mathbf{0 . 7 9}$ & 0.11 & 0.25 & 0.24 \\
\hline BP4 & $\mathbf{0 . 7 5}$ & 0.21 & 0.23 & 0.32 \\
\hline BP5 & $\mathbf{0 . 8 0}$ & 0.07 & 0.33 & 0.27 \\
\hline BP6 & $\mathbf{0 . 6 9}$ & 0.19 & 0.33 & 0.12 \\
\hline EM1 & 0.28 & $\mathbf{0 . 6 9}$ & 0.50 & 0.28 \\
\hline EM2 & 0.10 & $\mathbf{0 . 7 1}$ & 0.33 & 0.30 \\
\hline EM3 & 0.06 & $\mathbf{0 . 7 6}$ & 0.21 & 0.29 \\
\hline EM4 & 0.10 & $\mathbf{0 . 8 3}$ & 0.39 & 0.31 \\
\hline EM5 & 0.07 & $\mathbf{0 . 8 7}$ & 0.36 & 0.28 \\
\hline EM6 & 0.12 & $\mathbf{0 . 6 4}$ & 0.32 & 0.13 \\
\hline EM7 & 0.05 & $\mathbf{0 . 6 8}$ & 0.20 & 0.16 \\
\hline IM1 & 0.31 & 0.31 & $\mathbf{0 . 8 5}$ & 0.20 \\
\hline IM2 & 0.37 & 0.47 & $\mathbf{0 . 9 6}$ & 0.31 \\
\hline IM3 & 0.37 & 0.51 & $\mathbf{0 . 9 5}$ & 0.31 \\
\hline MP1 & 0.17 & 0.12 & 0.23 & $\mathbf{0 . 6 2}$ \\
\hline MP2 & 0.16 & 0.12 & 0.15 & $\mathbf{0 . 5 3}$ \\
\hline MP3 & 0.24 & 0.25 & 0.28 & $\mathbf{0 . 8 0}$ \\
\hline MP4 & 0.27 & 0.12 & 0.26 & $\mathbf{0 . 6 8}$ \\
\hline MP5 & 0.26 & 0.27 & 0.21 & $\mathbf{0 . 8 0}$ \\
\hline MP6 & 0.14 & 0.40 & 0.17 & $\mathbf{0 . 8 4}$ \\
\hline MP7 & 0.28 & 0.30 & 0.26 & $\mathbf{0 . 8 0}$ \\
\hline MP8 & 0.31 & 0.26 & 0.30 & $\mathbf{0 . 7 7}$ \\
\hline
\end{tabular}

BP: Budget Participation; Intrinsic: Intrinsic Motivation; Extrinsic: Extrinsic Motivation; MP: Job Performance

Table 3: Reliability, Average Variance Extracted (AVE) and Correlations

\begin{tabular}{|c|c|c|c|c|c|c|c|}
\hline & \multirow{2}{*}{ AVE } & Composite & Cronbach & \multicolumn{5}{|c|}{ Correlations } \\
\cline { 5 - 8 } & & Reliability & Alpha & BP & Intrinsic & Extrinsic & MP \\
\hline BP & 0.59 & 0.90 & 0.86 & $\mathbf{0 . 7 7}$ & & & \\
\hline Intrinsic & 0.85 & 0.95 & 0.91 & 0.38 & $\mathbf{0 . 9 2}$ & & \\
\hline Extrinsic & 0.55 & 0.89 & 0.86 & 0.17 & 0.47 & $\mathbf{0 . 7 4}$ & \\
\hline MP & 0.54 & 0.90 & 0.88 & 0.30 & 0.30 & 0.35 & $\mathbf{0 . 7 3}$ \\
\hline
\end{tabular}

Diagonal elements are the square roots of the AVE (bold). 
The Impact of Intrinsic and Extrinsic Motivation on Job Performance in a Participative Budget Setting: A Research Note

H1 hypothesizes the positive relationship between budget participation and intrinsic motivation. Figure 2 shows significant evidence to support the relationship $(\beta=0.38, p<0.01)$. For the relationship between intrinsic motivation and extrinsic motivation (H2), a significant positive relationship is also revealed $(\beta=0.47, \mathrm{p}<0.01)$. In addition, support has been found for $\mathrm{H} 3$ that hypothesizes the positive relationship between extrinsic motivation and job performance $(\beta=0.35, \mathrm{p}<0.01)$.

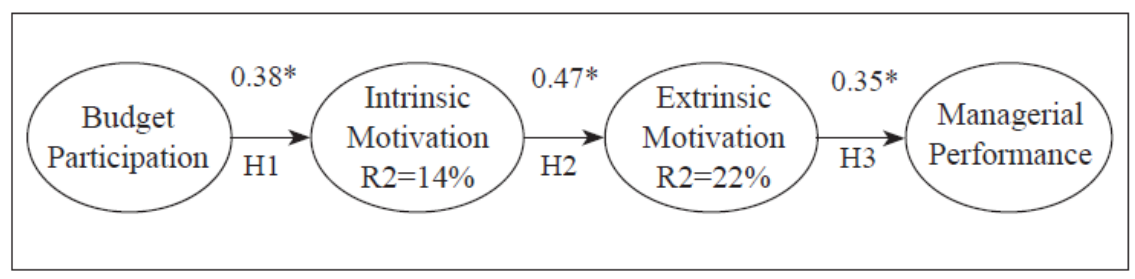

Figure 2: Path Coefficients of Theoretical Model

*significant at 0.01

\section{Discussion and Conclusion}

The objective of this study is to examine whether both forms of motivation intrinsic and extrinsic - have any impact on job performance in a participative budget setting. This study aims to bridge the gap in the extant literature by providing empirical evidence for the joint consideration of intrinsic and extrinsic motivation in the relationship between budget participation and job performance, and offering insights into which intrinsic and extrinsic motivation may enhance job performance. While previous studies also show similar findings in the relationship between budget participation and intrinsic motivation (Kenis, 1979; Merchant, 1981), and between extrinsic motivation and job performance (Brownell and McInnes, 1986), so far, no empirical study has examined the positive impact of intrinsic motivation on extrinsic motivation. This study contributes to the extant literature by providing empirical evidence that while budget participation increases intrinsic motivation, intrinsic motivation leads to higher extrinsic motivation, which, in turn, increases job performance.

As no consistent evidence was found in the previous studies concerning the relationship between budget participation and job performance (Merchant, 1981; Brownell, 1982; Brownell and McInnes, 1986, Kenis, 1979), this study may shed some light on the joint consideration played by motivation. Intrinsic and extrinsic motivations play the role in enhancing job performance in a participative budgeting setting.

Practically, the results may suggest that by involving managers in preparing the budget, it provides managers the opportunity to offer some views and to 
influence the budget. Since the budget is prepared based on the views and recommendations of the individual managers, it increases the motivation of the managers to accomplish the budget for their own personal satisfaction and selfaccomplishment. This leads to the higher motivation for extrinsic rewards, such as incentives, pay rise and appreciation from others. Consequently, it increases the job performance of managers.

However, the results of this study are subject to several limitations. Firstly, a cross-sectional survey usually does not provide evidence of the causal relationships between variables. Next, this study only examined the role of both forms of motivation - intrinsic and extrinsic - in the relationship between budget participation and performance. The relationship may be far more complex than the one investigated in this study.

\section{References}

Agbejule, A. and Saarikoski, L. (2006). The effect of cost management knowledge on the relationship between budgetary participation and managerial performance. The British Accounting Review, 38, 427-440.

Becker, S. and Green, D. (1962). Budgeting and employee behaviour. Journal of Business, 35(4), 392-402.

Brownell, P. (1982). A field study examination of budgetary participation and locus of control. The Accounting Review, 57(4), 766-777.

Brownell, P. (1983). The motivational impact of management-by-exception in a budgetary context. Journal of Accounting Research, 21(2), 456-472.

Brownell, P. and McInnes, M. (1986). Budgetary participation, motivation and managerial performance. The Accounting Review, 49(4), 587-600.

Chin W.W. (1998). The partial least square approach to structural equation modeling. In: G.A. Marcoulides (ed.) Modern Methods for Business Research. Erlbaum: Mahwah, NJ, pp. 295-336.

Chong, V.K. and Chong, K.M. (2002). Budget goal commitment and informational effects of budget participation on performance: a structural equation modeling approach. Behavioural Research in Accounting, 14, 65-86.

Chong, V. K. and Johnson, D. M. (2007). Testing a model of the antecedents and consequences of budgetary participation on job performance. Accounting and Business Research, 37(1), 3-19.

Deci, E.L. and Ryan, R.M. (1985). Intrinsic motivation and self-determination in human behaviour. New York: Plenum.

Dermer, J. (1975). The interrelationship of intrinsic and extrinsic motivation. Academy of Management Journal, 18(1), 125-130.

Fornell, C. and Larcker, D.F. (1981). Evaluating structural equation models with unobservable variables and measurement error. Journal of Marketing Research, 18, 39-50. 
Henseler, J., Ringle, C.M., and Sinkovics, R.R. (2009) The use of partial least squares path modeling in international marketing. Advances in International Marketing, 20, 277-319.

Hofstede, G. H. (1968). The Game of Budget Control, London: Assen Tavistock. Hsu, S.H., Chen, W.H. and Hsieh, M.J. (2006) Robustness testing of PLS, LISREL, EQS and ANN-based SEM for measuring customer satisfaction. Total Quality Management, 17(3), 355-371.

Hulland J. (1999). Use of partial least squares (PLS) in strategic management research: a review of four recent studies. Strategic Management Journal 20(2), 195-204.

Jermias, J. And Setiawan, T. (2008). The moderating effects of hierarchy and control systems on the relationship between budgetary participation and performance. The International Journal of Accounting, 43, 268-292.

Kenis, I. (1979). Effects of budgetary goal characteristics on managerial attitudes and performance. The Accounting Review, 54(4), 707-721.

Kren, L. (1990). Performance in a budget-based control system: an extended expectancy theory model approach. Journal of Management Accounting Research, 2, 100-112.

Lau, C.M. and Lim, E.W. (2002). The intervening effects of participation on the relationship between procedural justice and managerial performance. British Accounting Review, 34, 55-78.

Lau, C.M. and Sholihin, M. (2005). Financial and nonfinancial performance measures: how do they affect job satisfaction? The British Accounting Review, 37, 389-413.

Lau, C.M. and Tan, S.L.C. (2006). The effects of procedural fairness and interpersonal trust on job tension in budgeting. Management Accounting Research, 17, 171-186.

Lawler, E.E. and Suttle, J.L. (1973). Expectancy theory and job behaviour. Organisational Behaviour and Human Performance, 482-503.

Locke, E.A. and Latham, G.P. (1984). Goal setting: a motivational technique that works! Englewood Cliffs, NJ: Prentice-Hall.

Magner, N., Welker, R. B. and Campbell, T. L. (1995). The interactive effect of budgetary participation and budget favorability on attitudes toward budgetary decision makers: a research note. Accounting, Organisations and Society, 20(7/8), 611-618.

Mahoney, T. A., Jerdee, T. H. and Carroll, S. J. (1965). The jobs of management. Industrial Relations, 97-110.

Merchant, K.A. (1981). The design of the corporate budgeting system: influences on managerial behaviour and performance. The Accounting Review, 56, 813-829.

Milani, K. (1975). The relationship of participation in budget-setting to industrial supervisor performance and attitudes: a field study. The Accounting Review, 50(2), 274-284. 
Nouri, H. and Parker, R.J. (1998). The relationship between budget participation and job performance: the roles of budget adequacy and organisational commitment. Accounting, Organisations and Society, 23(5/6), 467-483.

Parker, R. J. and Kyj, L. (2006). Vertical information sharing in the budgeting process. Accounting, Organisations and Society, 31, 27-45.

Ryan, R.M. and Deci, E.L. (2000). Intrinsic and Extrinsic Motivations: Classic Definitions and

New Directions. Contemporary Educational Psychology, 25, 54-67.

Shields, J. F. and Shields, M.D. (1998). Antecedents of participative budgeting. Accounting, Organisations and Society, 23(1), 49-76.

Wong-On-Wing, B., Guo, L. and Lui, G. (2010). Intrinsic and extrinsic motivation and participation in budgeting: antecedents and consequences. Behavioural Research in Accounting, 22(2), 133-153. 